Vol. 12, No. 1

ISSN: 2085 - 4609 (Print), e- ISSN 2656-0208

Journal homepage: bit.ly/UltimaComm

\title{
Melihat Perbincangan \#Pilpres2019 di Media Sosial dengan Social Media Analytics
}

\section{Yearry Panji Setianto}

To cite this article:

Setianto, Y.P. (2020). Melihat Perbincangan \#Pilpres2019 di Media Sosial dengan Social Media Analytic, 12(1), 1433. https://doi.org/10.31937/ultimacomm.v12i1.1088

Ultimacomm publishes research articles and conceptual paper in the field of communication, mainly digital journalism and strategic communication. It is published twice a year by the Faculty of Communication of Universitas Multimedia Nusantara 


\title{
Melihat Perbincangan \#Pilpres2019 di Media Sosial dengan Social Media Analytics
}

\author{
Yearry Panji Setianto \\ Universitas Sultan Ageng Tirtayasa, Banten \\ Email: yearry@untirta.ac.id
}

Received Apr 26, 2019; Revised on Mar. 12, 2020, Accepted Apr. 16, 2020

\begin{abstract}
Abstrak
Riset deskriptif ini berupaya menjelaskan tentang partisipasi warganet dalam membicarakan beragam topik politik seputar Pemilihan Umum 2019 di Indonesia. Dengan mengambil kasus diskusi online di platform media sosial Twitter, peneliti menganalisis sejumlah hashtag terkait dengan kampanye online dari kedua pasangan calon presiden dan wakil presiden, Joko Widodo-Ma'ruf Amin dan Prabowo Subianto-Sandiaga Uno. Menggunakan metode penelitian social network analytics, peneliti menemukan bahwa diskusi online di Twitter dalam sejumlah topik seperti \#DebatPilpres2019, \#PrabowoMenangDebat dan \#DebatPintarJokowi seringkali didominasi oleh akun-akun yang tidak selalu popular serta tidak selalu dilakukan oleh 'buzzer' politik; meskipun akun @jokowi dan @prabowo masih merupakan dua tokoh utama yang diperbincangkan dalam diskusi tersebut. Dalam konteks ini, peneliti melihat bahwa media sosial semacam Twitter dapat berperan sebagai mini-publics, di mana diskursus yang hadir tidak harus selalu sejalan dengan wacana dominan (di media massa maupun di masyarakat luas). Selain itu, partisipasi masyarakat dalam berbincang soal politik juga dapat dimaknai sebagai praktik online politics yang tidak kalah pentingnya dalam proses demokratisasi di Indonesia.
\end{abstract}

Kata Kunci: komunikasi politik, hashtag politics, social media analytics, online politics

\begin{abstract}
This descriptive study aims to explain how netizens discuss various topics related to the 2019 General Election in Indonesia. By taking the case of online discussion on social media platform of Twitter, the author examines some hashtags related to the online campaign of two running president and vice-president candidates, Joko Widodo-Ma'ruf Amin and Prabowo SubiantoSandiaga Uno. Utilizing social network analytics, the author found that online conversations on Twitter regarding the topics of \#DebatPilpres2019, \#PrabowoMenangDebat and \#DebatPintarJokowi most of the time are dominated by not-so-called popular accounts and might not be associated as political 'buzzers.'; although the Twitter accounts of @jokowi and @prabowo are found to be two most discussed actors within the conversation. Here, the author argues that social media platforms like Twitter serve as mini-publics-where the discourse here is not always in parallel with the mainstream (mass media or people's) opinion. Moreover, people's engagement in political talks on social media as online politics should not be considered as less than an important part of the democratization process in Indonesia.
\end{abstract}

Key words: political communication, hashtag politics, social media analytics, online politics 


\section{PENDAHULUAN}

Penggunaan media sosial sebagai platform komunikasi politik sebenarnya bukanlah suatu fenomena yang baru. Dalam konteks politik di Amerika Serikat, Pemilihan Presiden pada 2008 yang lalu disebut sebagai salah satu cikal bakal penggunaan media sosial oleh para politisi secara massive (Takaragawa \& Carty, 2012). Barrack Obama juga disebut oleh sejumlah peneliti sebagai salah satu tokoh politik yang paling sukses dalam berkomunikasi melalui media sosial dengan para konstituennya (Bimber, 2014; Gerodimos \& Justinussen, 2014). Praktik semacam ini nantinya berkembang di banyak negara, termasuk juga di Indonesia. Riset ini berupaya untuk melihat sejauh mana warganet sebagai ordinary citizens terlibat dalam perbincangan di media sosial selain sebagai bentuk komunikasi politik juga sebagai ruang alternatif dalam artikulasi politik mereka dalam konteks mediatized politics.

Riset tentang penggunaan media sosial di Indonesia sejauh ini lebih banyak membahas tentang bagaimana para politisi menggunakan beragam platform guna menyampaikan pesan politik kepada khalayak luas; baik ditinjau sebagai praktik marketing politik ataupun political branding. Dalam kajian yang lebih luas lagi, Lim (2013) misalkan membahas tentang bagaimana media sosial seringkali digunakan oleh beragam lapisan masyarakat guna mengangkat isu-isu sosial politik. Dua kasus yang ditelaah oleh Lim, yaitu tentang gerakan 'Koin untuk Prita' dan gerakan 'Cicak versus Buaya' dapat dijadikan contoh bagaimana masyarakat Indonesia mulai sadar peran media sosial dalam menyuarakan kepentingan mereka-yang mungkin selama ini tidak sepenuhnya dapat diwadahi oleh media massa arus utama maupun ruang publik lainnya.

Artikel riset ini akan lebih banyak membahas tentang Twitter sebagai medium yang mulai kembali diminati oleh masyarakat di Indonesia dalam berbincang tentang isu sosial politik. Dalam argumentasi peneliti, Twitter lebih cocok untuk digunakan sebagai ruang diskusi dengan mengandalkan unsur teks (meskipun kini juga dilengkapi fitur visual karena pengguna juga dimungkinkan untuk mengunggah foto, meme, ataupun GIF file). Selain itu, Vromen (2017) menjelaskan bahwa jika dibandingkan dengan platform media sosial lainnya, Twitter lebih didominasi oleh para pengguna yang pada dasarnya aktif secara politik dan juga aktif mengonsumsi berita. Lebih dari itu, Wojcieszak dan Mutz (2009) berpendapat bahwa perbincangan politik di Twitter pada dasarnya berkesinambungan dengan perbincangan rutin sehari-hari, sehingga diharapkan dapat lebih mendorong diskursus politik yang lebih berkualitas. Diskusi sosial politik di Twitter juga seringkali menjadi sorotan bagi media massa ketika sejumlah hashtag menjadi trending topic di platform ini, terutama karena jurnalis semakin mengandalkan media sosial sebagai sumber berita mereka (Bruns, Enli, Skogerb $\varnothing$, Larsson \& Christensen, 2016); selain juga muncul kecenderungan jurnalis dan politisi sama-sama memanfaatkan hashtag di Twitter guna melebarkan jaringan professional mereka (Enli \& Simonsen, 2018). Hashtag menjadi fokus kajian yang penting karena: 
"They are a technic (which is to say, both a technique and a technology) of the social, and in their performativity are events that map together and encompass not just the tag itself but the network of human and nonhuman actors that come together in such configurations: tags, technologies, taggers, conversations, press coverage in other media." (Rambukkana, 2015, pp. 4-5)

Untuk itu, peneliti akan membahas tentang bagaimana praktik komunikasi politik yang terkait dengan sejumlah hashtag menjelang Pemilihan Umum Presiden dan Legislatif 2019, terutama hashtags yang menjadi arena diskusi sekaligus debat bagi para warganet di Indonesia guna menyuarakan dukungan politik mereka masing-masing.

\section{TINJAUAN PUSTAKA}

\section{Internet, Media Sosial dan Isu Sosial-Politik di Indonesia}

Hill dan Sen (2005) membahas secara lengkap tentang cikal bakal penggunaan internet sebagai medium bagi masyarakat Indonesia guna berpartisipasi dalam beragam isu sosial, budaya, serta politik. Mereka mencatat bahwa jika sebelumnya, di era Orde Baru, media massa tradisional seperti surat kabar dan televisi masih terlalu banyak dipengaruhi oleh rezim yang berkuasa, maka kehadiran internet menjadi alternatif bagi sebagian masyarakat terdidik guna membahas permasalahan sosial politik Indonesia di masa itu. Hill dan Sen mencontohkan, mailing list Apakabar yang beranggotakan sekitar 250,000 orang yang tersebar di 96 negara digunakan oleh para aktivis maupun mereka yang peduli dengan politik di Indonesia untuk bertukar berita, informasi dan analisis tentang situasi politik di Indonesia.

McDaniel (2002) berargumen bahwa pemerintah Indonesia di saat itu dianggap terlalu terlena dan meremehkan kekuatan sosial politik internet. Ketika akhirnya rezim Suharto berhasil dijatuhkan oleh gerakan mahasiswa pada 1998, salah satu faktor pendorongnya adalah kehadiran internet yang berhasil menumbuhkan kesadaran di sebagian masyarakat soal buruknya rezim otoriter Orde Baru. Berkaca dari kasus di Indonesia, McDaniel lebih lanjut menjelaskan bahwa pemerintah di negara Asia Tenggara lainnya seperti Malaysia dan Singapura melakukan kontrol yang lebih ketat terhadap penggunaan media sosial dalam konteks politik. Beruntung bagi masyarakat Indonesia, setelah era reformasi, internet (masih) dianggap sebagai salah satu medium yang minim kontrol dari pemerintah dalam soal isu sosial dan politik; selain bahwa Indonesia masih belum memiliki regulasi yang tepat dan komprehensif soal akses dan tata kelola internet di era global-transnasional saat ini (Setianto, 2015).

Oleh karenanya, ketika media sosial mulai hadir di Indonesia, banyak dari masyarakat yang mengalami kebingungan dalam beradaptasi dengan medium ini. Kehadiran fenomena semacam kelompok-kelompok radikal di online groups, penyebaran berita palsu, sirkulasi video tutorial dalam pembuatan bom, hingga prostitusi online melalui media sosial dianggap sebagai bentuk ketidakdewasaan masyarakat di Indonesia terkait dengan media online. Meskipun demikian, Kementerian Komunikasi dan Informasi 
(Kominfo) telah menggunakan Undang-Undang Informasi dan Transaksi Elektronik (UU ITE) sebagai dasar hukum guna mengatur penggunaan internet, termasuk media sosial di Indonesia.

Sayangnya, regulasi semacam ini juga dianggap sebagai ancaman bagi kebebasan berekspresi bagi banyak pihak. Dalam hal politik, dikhawatirkan bahwa pasal-pasal di dalam UU ITE dapat digunakan untuk membungkam pihak-pihak yang dianggap melakukan kritik terhadap penguasa maupun politisi tertentu. Menariknya, hal ini tidak menghentikan semangat para warnaget di Indonesia, terlebih lagi dalam membicarakan politik. Buktinya adalah perbincangan tentang pelbagai topik politik, mulai dari yang serius hingga yang banal, masih menjadi praktik yang ramai dilakukan di media sosial semacam Twitter. Perang hashtag dalam mendukung satu pasangan calon presiden dan wakil presiden masih menjadi fenomena yang ramai terjadi, khususnya menjelang pelaksanaan Pemilihan Umum Presiden dan Legislatif pada April 2019.

\section{Twitter dan Kampanye Politik}

Media sosial banyak dipahami sebagai ancaman bagi suatu rezim sehingga dalam sejumlah kesempatan akses terhadap platform ini semakin dipersulit di suatu negara. Tufekci (2017) membuat penelitian mendalam tentang peran media sosial sebagai medium yang digunakan sebagai penghubung jaringan anggota masyarakat dalam bentuk protes sosial dan politik. Menurutnya, media sosial bahkan memiliki 'capacity' dalam mengganggu status quo, mengubah kebijakan atau menciptakan perubahan struktural. Salah satu contoh yang dijabarkan oleh Tufekci adalah bagaimana media sosial berperan besar dalam menjatuhkan regime dalam konteks Arab Spring pada 2011 yang lalu.

Lim (2012) menegaskan bahwa peran media sosial dalam revolusi sosial politik, seperti dalam kasus Arab Spring di Mesir, bukan sekedar sebagai 'teknologi' tapi juga berperan secara 'sosial-politik'. Lim (2012, p. 4) menambahkan bahwa, "social media represent tools and spaces in which various communication networks that make up social movement emerge, connect, collapse, and expand." Meskipun menolak untuk menyebutkan media sosial sebagai satu-satunya atau platform utama sirkulasi informasi (terkait mobilisasi politik dalam menjatuhkan rezim Hosni Mubarak), Lim mengakui bahwa media sosial membantu gerakan yang menuntut perubahan politik tersebut dengan cara membuka lebar ruang partisipasi publik.

Di sisi lain, masyarakat juga banyak memperoleh informasi politik melalui media sosial seperti following aktor politik di Twitter, di mana praktik semacam ini biasanya dilakukan oleh para pendukung partai politik tertentu yang mereka rasa sesuai dengan pemikiran politik mereka masing-masing (Gainous \& Wagner, 2014). Para aktor politik pada saat yang sama melihat bahwa kehadiran mereka di dunia offline juga perlu diperluas hingga ke ranah online, sehingga mereka yang umumnya populer dalam konteks politik offline juga (akan) mendominasi ranah politik online, khususnya di media sosial. Menurut Klinger (2013), dominasi diskursus politik online di media sosial sedikit banyak dipengaruhi oleh sumber daya yang dimiliki oleh tiap-tiap partai politik. Sehingga, tidak mengherankan jika tokoh politik dari partai politik besar seringkali mendominasi diskusi politik online atau di 
media sosial. Temuan yang berbeda terjadi di Jerman ketika partai minoritas di sana justru menjadi partai yang paling berpengaruh di Twitter selama Kampanye Politik di tahun 2009 (Jürgens \& Jungherr, 2015). Hal ini menunjukkan bahwa media sosial semacam Twitter masih memberikan ruang yang demokratis bagi setiap aktor politik maupun masyarakat biasa (sebagai konstituen) untuk berpartisipasi dalam perbincangan politik secara online.

Lalu, sejauh mana fenomena komunikasi politik semacam ini diteliti oleh kalangan akademik? Jungherr (2016) membuat pemetaan yang cukup komprehensif tentang 127 riset yang secara spesifik membahas tentang penggunaan Twitter dalam kampanye politik. Dalam risetnya, Jungherr membagi sejumlah penelitian tersebut ke dalam tiga kategori besar: parties/candidates (penggunaan Twitter oleh partai politik dan para kandidat yang ikut berkompetisi dalam pemilihan umum), publics (penggunaan Twitter oleh publik yang vokal dalam isu politik/kampanye), dan events (penggunaan Twitter terkait dengan peristiwa politik semasa kampanye politik).

Jungherr (2016) menjelaskan bahwa dalam riset kategori parties/candidates, umumnya ada tiga aspek yang menjadi fokus utama penelitian: karakteristik dari partai politik atau para kandidat yang mengadopsi Twitter sebagai medium politik, bagaimana mereka menggunakan Twitter sebagai medium politik, serta sejauh mana efektivitas penggunaan Twitter sebagai alat komunikasi politik oleh mereka. Sementara dalam konteks riset Twitter publics, ia menambahkan bahwa fokus kajian lebih mengarah kepada analisis bagaimana masyarakat mengunggah pesan-pesan politik menggunakan hashtag atau frase yang relevan dengan konteks politik tertentu, atau para pengguna Twitter yang mengikuti para aktor/partai politik secara online. Lebih lanjut, Jungherr memaparkan bahwa dalam konteks mediated events, peneliti banyak tertarik pada peristiwa seputar kampanye politik seperti siaran langsung debat antar kandidat di televisi, pemberitaan seputar kampanye, dan semacamnya.

Sayangnya, dari sekian banyak riset tentang Twitter dan kampanye politik, masih sedikit penelitian yang mengangkat fenomena diskusi politik di media sosial di Indonesia. Dalam temuan Jungherr (2016), dari 127 riset yang dilakukan di 26 negara berbeda tersebut, hanya ditemukan satu penelitian tentang Twitter dan kampanye politik di Indonesiayaitu riset milik Amirullah, Komp dan Nurhadryani (2013), yang membahas tentang parties/candidates. Untuk itu, penelitian kali ini bertujuan untuk mengisi research gaps tentang riset perbincangan politik melalui Twitter dalam konteks Pemilihan Umum 2019 di Indonesia dengan menggunakan kombinasi dua kategori dari Jungherr (2016), terutama Twitter publics dan mediated events.

\section{METODE}

Riset ini menggunakan pendekatan deskriptif kualitatif guna memahami praktik penggunaan hashtag oleh Twitter publics sebagai strategi artikulasi politik di media sosial seputar mediated event Pemilihan Presiden 2019 di Indonesia. Metode penelitian yang 
digunakan adalah social network analytics dengan fokus tiga hashtag yang peneliti anggap relevan dengan tema yang diteliti, yaitu \#DebatPilpres2019, \#PrabowoMenangDebat, dan \#DebatPintarJokowi. Metode ini dipilih guna mengetahui lebih lanjut tentang bagaimana jaringan diskusi terbentuk dalam masing-masing hashtag tadi, juga sebagai upaya identifikasi siapa saja yang dianggap lebih vokal dalam artikulasi politik dalam konteks Pemilihan Presiden 2019 ini.

Seluruh data dikumpulkan selama berlangsungnya acara Debat Kedua Pemilihan Presiden 2019 pada Minggu, 7 Februari 2019 yang pada saat yang bersamaan disiarkan secara langsung di televisi nasional-sehingga termasuk ke dalam kategori mediated events sebagaimana yang dimaksud oleh Jungherr (2016). Fase debat ini menjadi menarik karena hanya menghadirkan kedua kandidat presiden tanpa wakil mereka. Jadi, melalui debat ini publik diharapkan dapat lebih melihat ide dan kapasitas personal dari kedua calon presiden tersebut. Sejumlah isu yang dibahas di dalam debat antara lain tentang infrastruktur, energi, hingga sumber daya alam.

Data dikumpulkan dengan strategi data mining menggunakan software NodeXL Pro dan Twitter Public API. Dengan menggunakan NodeXL Pro, peneliti (hanya) berhasil mengumpulkan kurang lebih 18,000 tweets dari masing-masing hashtag-terutama karena batas angka ini yang diperbolehkan oleh software tersebut. Setelah seluruh data berhasil dikumpulkan, peneliti menggunakan sejumlah fitur kalkulasi guna 'mengukur' jaringan yang terbentuk dalam tiap-tiap hashtag seperti density (untuk mengetahui jarak atau kerapatan dari suatu jaringan), degree (angka keterhubungan antar aktor dalam suatu jaringan), dan modularity (kualitas jaringan yang dapat merefleksikan terbentuknya kelompok/cluster). Sayangnya, karena visualisasi data yang dimiliki oleh NodeXL Pro cenderung kaku dan kurang komunikatif, maka peneliti memindahkan data jaringan ini ke dalam software Gephi yang memang secara khusus ditujukan untuk visualisasi data jaringan (network visualization).

\section{HASIL DAN PEMBAHASAN}

\section{Kasus Pertama: \#DebatPilpres2019}

Selama acara Debat Calon Presiden 2019 pada 17 February 2019, setidaknya ada 116,000 tweets yang diunggah oleh masyarakat menggunakan hashtag \#DebatPilpres2019 untuk menyikapi, mendukung, memberi komentar, atau sekedar ikut membicarakan isu tersebut.

Berbeda dengan acara pada debat pasangan calon presiden dan wakil presiden yang pertama pada Januari 2019, acara debat kedua ini hanya menghadirkan kedua calon presiden yaitu Joko Widodo dan Prabowo Subianto. Topik yang diangkat juga berbeda dengan debat yang pertama. Kali ini, isu yang menjadi bahasan dalam debat keduanya adalah tentang isu energi, pangan, lingkungan dan infrastruktur. 
Gambar 1. Analisis Jaringan \#DebatPilpres2019

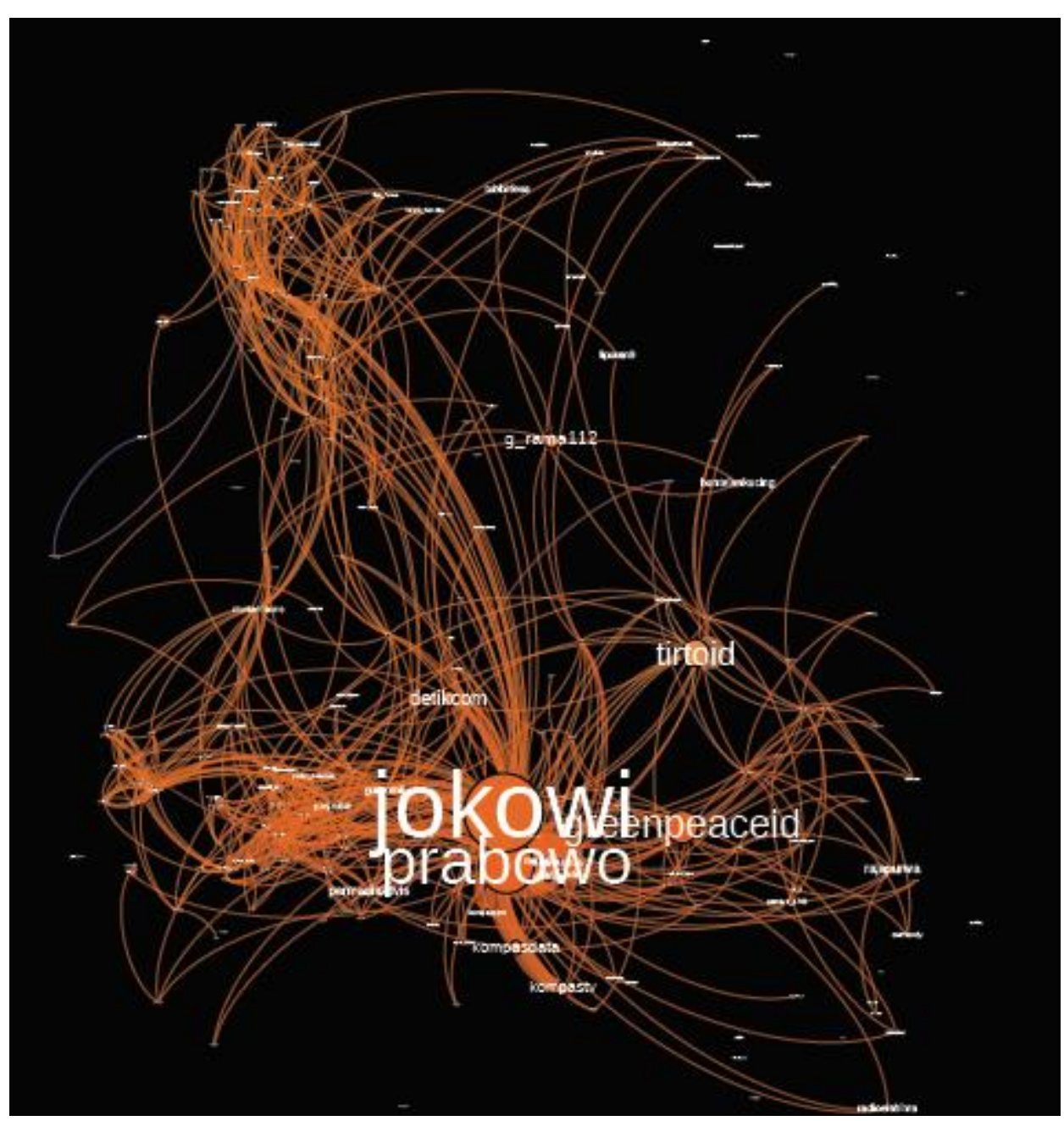

Analisis pada penggunaan hashtag \#DebatPilpres2019 ini setidaknya menggunakan sampel data dari 11.814 nodes (atau jumlah akun yang mengunggah pesan di Twitter) dan 23.484 edges (atau interaksi yang dilakukan oleh dua atau lebih nodes) yang diambil secara random menggunakan Twitter Public API. Kemudian, dari analisis modularity diketahui bahwa dalam jaringan ini ada sekitar 1.266 clusters atau kelompok kecil yang terbentuk oleh perbincangan warganet menggunakan hashtag \#DebatPilpres2019. Misalkan, di posisi tengah kanan jaringan, ada satu klaster yang terpusat pada akun @ tirtoid yang membentuk kelompok kecil sendiri yang 'terpisah' dari klaster di pojok kiri atas. Lebih dari itu, jika dilihat dari social network analysis (analisis jaringan media sosial) terkait dengan perbincangan dengan menggunakan hashtag \#DebatPilpres2019 ada sejumlah hal yang menarik untuk dibahas lebih lanjut. 
Pertama, dari segi degree atau seberapa penting seseorang (atau akun Twitter) dalam perbincangan di dalam jaringan media sosial, tidak mengherankan jika kedua sosok calon presiden, Jokowi dan Prabowo memiliki posisi yang signifikan. Dalam Gambar 1. dapat dilihat bahwa akun @jokowi dan @prabowo memiliki node size yang lebih besar dari akun lainnya. Dari kolom in-degree -- dapat diartikan sebagai seberapa sering sebuah akun dirujuk atau disebut (mentioned) -- juga dapat didapatkan informasi bahwa @jokowi, @prabowo,dan @greenpeaceid merupakan tiga akun utama yang paling sering dirujuk dalam diskusi tentang \#DebatPilpres2019 tersebut. Akun @greenpeaceid di sini muncul karena isu yang dibicarakan adalah isu lingkungan, padahal dalam diskusi debat sebelumnya di Januari 2019 akun ini sama sekali tidak relevan.

Tabel 1. Ranking Akun Twitter dalam \#DebatPilpres2019

\begin{tabular}{|c|l|r|r|r|r|}
\hline Rank & \multicolumn{1}{|c|}{ Account } & In-degree & Followers & Followed & Tweets \\
\hline 1 & jokowi & 2883 & 10908312 & 59 & 1465 \\
\hline 2 & prabowo & 1993 & 3596268 & 1988 & 8827 \\
\hline 3 & greenpeaceid & 1178 & 907517 & 1088 & 20588 \\
\hline 4 & tirtoid & 969 & 239153 & 44 & 46433 \\
\hline 5 & detikcom & 564 & 14944830 & 28 & 1438397 \\
\hline 6 & g_rama112 & 537 & 48 & 297 & 1974 \\
\hline 7 & kompasdata & 473 & 6371 & 106 & 7104 \\
\hline 8 & kompastv & 448 & 2702577 & 556 & 348916 \\
\hline 9 & permadiaktivis & 355 & 66015 & 738 & 8108 \\
\hline 10 & rajapurwa & 355 & 41810 & 3578 & 59750 \\
\hline 11 & buntelankucing & 308 & 549 & 418 & 2130 \\
\hline 12 & radioelshinta & 292 & 3597409 & 22 & 1002964 \\
\hline 13 & tubbirfess & 289 & 67836 & 4310 & 17935 \\
\hline 14 & liputan9 & 282 & 950967 & 9 & 26124 \\
\hline
\end{tabular}

Kedua, ada sejumlah akun media sosial milik organisasi media yang juga muncul dalam analisis jaringan \#DebatPilpres2019, yaitu akun @tirtoid (menempati urutan keempat) @detikcom (kelima), @kompasdata (ketujuh), @kompastv (kedelapan), dan @ radioelshinta (keduabelas). Temuan ini menjadi penting karena dua hal utama: organisasi media masih memiliki relevansi yang cukup tinggi dalam perbincangan tentang debat calon presiden, dan juga organisasi media masih dirujuk dalam perbincangan tersebut. Artinya, masyarakat yang membicarakan tentang isu politik masih memberikan ruang kepada organisasi media dalam mencari fakta ataupun sekedar melakukan konfirmasi atas apa yang dibicarakan oleh aktor politik. Dengan kata lain, organisasi media dapat menjadi medium fact-checking bagi pengguna media sosial terkait dengan opini atau gagasan yang disampaikan baik oleh Jokowi maupun Prabowo saat debat berlangsung. Hal ini dapat ditemukan dalam sejumlah ungguhan yang membahas pesan yang disampaikan oleh masing-masing kandidat yang kemudian disertai tautan berita sebagai sanggahan dari pesan tersebut. Meskipun demikian, ditemukan juga dua akun parodi seperti @tubbirfess dan @liputan9 yang juga banyak dipakai oleh warganet 
sebagai rujukan (ataupun akun yang ikut dibahas) saat mereka membicarakan tentang debat antara Jokowi dan Prabowo. Kedua akun parodi ini memiliki degree yang tinggi lebih dikarenakan tidak semua pengguna Twitter mengunggah pesan mereka secara serius sehingga mereka memilih untuk menanggapinya sebagai hiburan atau lelucon dengan memberikan tautan kepada akun parodi semacam @tubbirfess dan @liputan9.

Ketiga, jika disimak dari isi pesan yang diunggah ke dalam Twitter, mayoritas pesan membahas tentang jalannya debat maupun materi yang disampaikan oleh para kandidat. Mereka memperhatikan tentang isu lingkungan, isu kepemilikan lahan oleh salah satu kandidat dan semacamnya. Hanya saja, serupa dengan mereka yang menghubungkan unggahan politik mereka dengan akun parodi, tidak semua pesan yang diunggah bernada serius karena banyak juga pesan yang disampaikan dengan gaya humor seperti mereka yang mengaitkan debat calon presiden dengan girl band Korea Selatan, BLACKPINK ataupun yang menyindir salah satu kandidat tentang unicorn. Selain itu, tidak banyak debat yang muncul di antara pendukung dari kedua kandidat karena sebagian besar lebih berupaya menyampaikan pandangan politik dan dukungan kepada masing-masing calon pilihannya. Artinya, pesan dalam konteks hashtag ini lebih bersifat searah (unidirectional).

Tabel 2. Contoh Isi Pesan dalam \#DebatPilpres2019

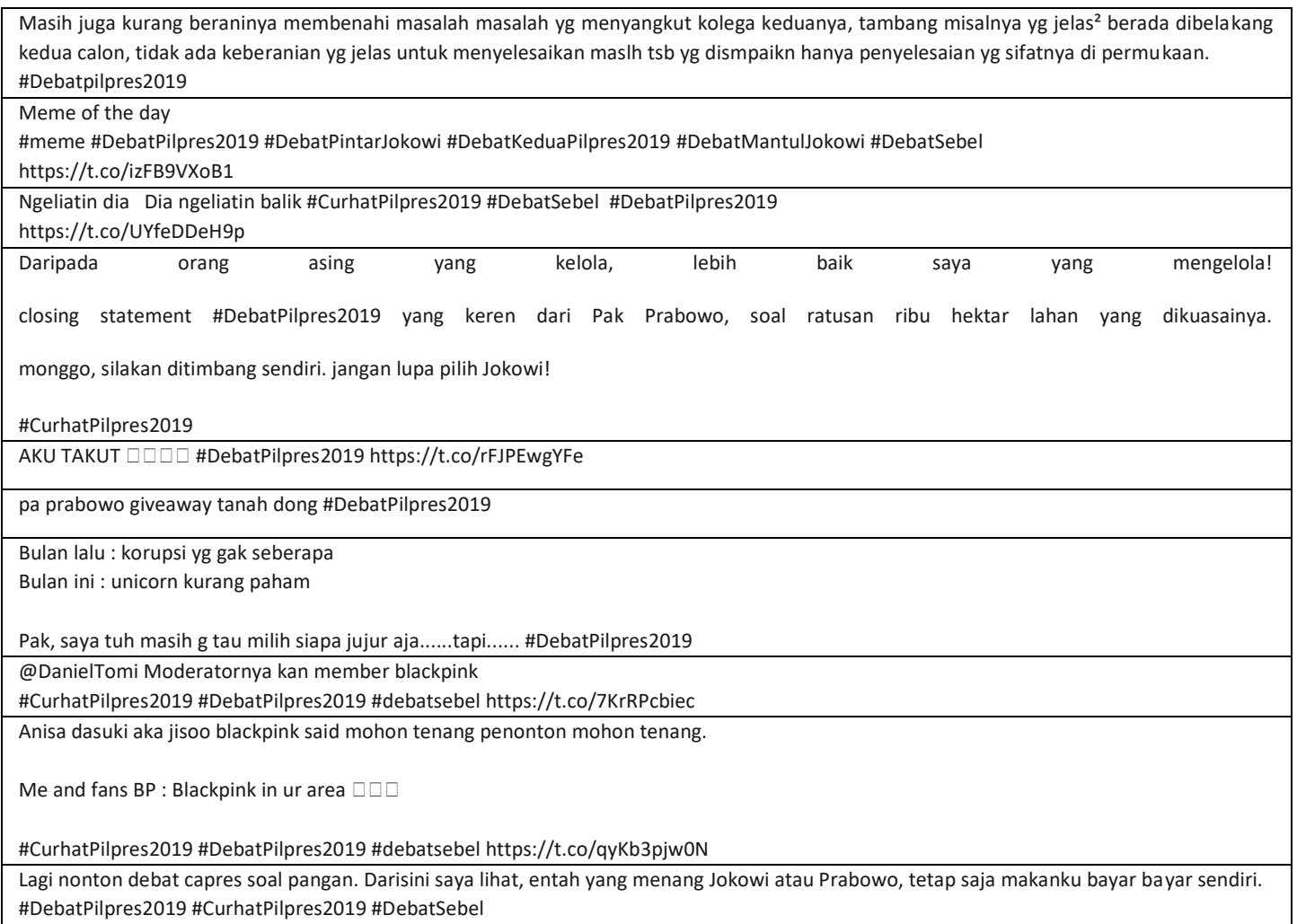




\section{Kasus Kedua: \#PrabowoMenangDebat}

Masih terkait dengan acara debat calon presiden 2019, hashtag kedua yang akan dibahas di sini adalah \#PrabowoMenangDebat di mana isi pesan yang diunggah melalui Twitter akan lebih condong kepada pendukung ataupun mereka yang membicarakan kandidat presiden Prabowo Subianto. Gaya komunikasi melalui hashtag semacam ini umumnya digagas oleh pendukung kandidat tertentu, dalam kasus ini pendukung dari calon presiden Prabowo Subianto. Dalam analisis jaringan hashtag ini, yang menarik adalah bukan hanya akun @prabowo menjadi node yang paling dominan, tapi juga jika dilihat dari modularity (atau gugus kelompok yang terbentuk dalam jaringan) perbincangan cenderung didominasi oleh satu kelompok besar berwarna merah (klaster utama). Meskipun demikian, klaster lainnya (dengan warna selain merah) masih dapat terlihat, misalkan merujuk kepada akun @pollinglagi dan @gerindra (lihat Gambar 2). Klaster minor lainnya juga melibatkan akun partai politik lain seperti @nasdem dan @pdemokrat. Secara umum, hashtag ini digunakan oleh setidaknya 10.645 nodes dan menghasilkan 29.157 edges.

Gambar 2. Analisis Jaringan \#PrabowoMenangDebat

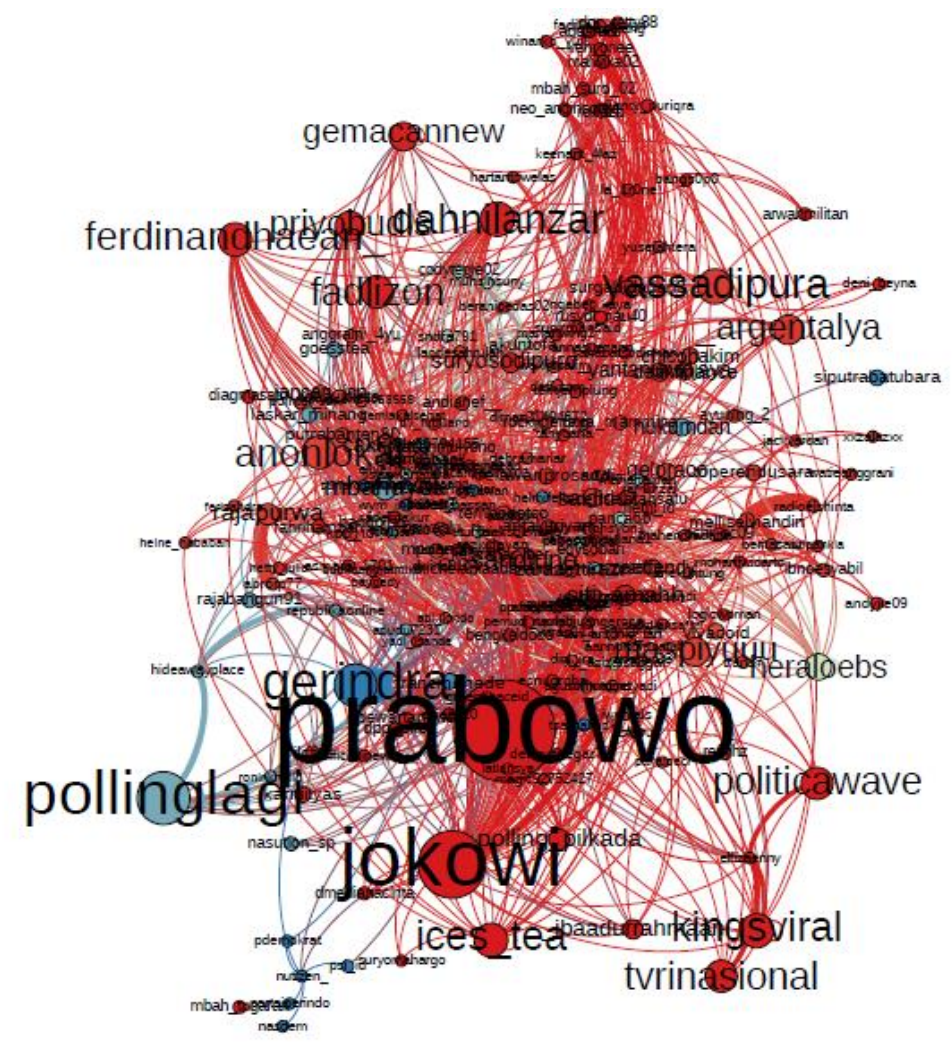


Tabel 3. Ranking Akun Twitter dalam \#PrabowoMenangDebat

\begin{tabular}{|c|l|r|r|r|r|}
\hline Rank & \multicolumn{1}{|c|}{ Account } & In-degree & \multicolumn{1}{c|}{ Followers } & \multicolumn{1}{c|}{ Followed } & \multicolumn{1}{c|}{ Tweets } \\
\hline 1 & prabowo & 2106 & 3616327 & 1988 & 8827 \\
\hline 2 & jokowi & 1318 & 10933290 & 59 & 1475 \\
\hline 3 & pollinglagi & 984 & 34090 & 0 & 1154 \\
\hline 4 & gerindra & 745 & 382766 & 4003 & 84799 \\
\hline 5 & yassadipura & 572 & 1390 & 916 & 5949 \\
\hline 6 & dahnilanzar & 557 & 206040 & 1018 & 45754 \\
\hline 7 & kingsviral & 547 & 20760 & 3532 & 42322 \\
\hline 8 & ferdinandhaean_ & 539 & 13081 & 353 & 443 \\
\hline 9 & ices_tea & 532 & 8292 & 1225 & 44935 \\
\hline 10 & anonlokal & 527 & 12240 & 162 & 13623 \\
\hline 11 & fadlizon & 516 & 1087891 & 1106 & 46041 \\
\hline 12 & politicawave & 509 & 15158 & 0 & 8510 \\
\hline 13 & tvrinasional & 508 & 73541 & 393 & 29273 \\
\hline 14 & priyobudis & 450 & 171978 & 840 & 11615 \\
\hline
\end{tabular}

Berdasarkan Tabel 3 di atas, \#PrabowoMenangDebat memang didominasi oleh penyebutan @prabowo dalam mayoritas unggahan di Twitter. Uniknya, akun @jokowi juga tidak kalah penting posisinya di dalam hashtag yang dimaksud. Jika dilihat secara seksama, banyak dari pesan yang diunggah oleh pendukung calon presiden Prabowo ternyata tidak sedikit yang juga menyinggung Jokowi. Praktik ini tentunya bukan sesuatu yang tidak disengaja karena dalam konteks 'perang hashtag' hal semacam ini lazim dilakukan guna menyerang kubu lawan politik.

Selain itu, sejumlah akun yang merujuk kepada aktor politik pendukung calon presiden Prabowo Subianto juga terlihat berada di posisi yang signifikan. Misalkan saja, akun yang dimiliki oleh Partai Gerindra (peringkat keempat), Tim Pemenangan pasangan PrabowoSandi, Dahnil Anzar (peringkat keenam), dan Wakil Ketua Partai Gerindra Fadli Zon (peringkat kesebelas) juga termasuk tokoh-tokoh politik yang dominan dirujuk dalam hashtag \#PrabowoMenangDebat. Contoh ini juga menunjukkan bahwa tim kampanye pasangan Prabowo dan Sandiaga Uno dapat disebut cukup aktif di media sosial Twitter, termasuk dalam mempromosikan pesan-pesan tertentu dalam konteks kampanye dan debat politik menjelang Pemilihan Umum 2019.

Tabel 4. Ranking Out-degree Akun Twitter dalam \#PrabowoMenangDebat

\begin{tabular}{|c|c|c|c|c|c|}
\hline Rank & Account & Out-degree & Followers & Followed & Tweets \\
\hline 1 & siti_amahh & 235 & 42 & 68 & 2133 \\
\hline 2 & melliselviandin & 105 & 864 & 122 & 55881 \\
\hline 3 & aufal_triyani & 101 & 86 & 137 & 4166 \\
\hline 4 & rollezb & 67 & 102 & 371 & 1179 \\
\hline 5 & edysobari & 67 & 1752 & 1831 & 17029 \\
\hline 6 & mbah_suro_02 & 58 & 457 & 660 & 7431 \\
\hline 7 & neo_anginsorga & 54 & 158 & 211 & 6111 \\
\hline 8 & dianty_nuriqra & 53 & 17 & 75 & 420 \\
\hline 9 & la_1rOne & 52 & 697 & 777 & 3134 \\
\hline 10 & kenyoriee & 50 & 3024 & 3803 & 40011 \\
\hline 11 & malwika02 & 50 & 1211 & 2629 & 2171 \\
\hline
\end{tabular}


Faktor lain yang juga perlu dipertimbangkan dalam melakukan analisis terhadap pola komunikasi politik dalam hashtag politik adalah siapa atau akun apa saja yang dianggap aktif dalam menyebutkan (atau mention) akun lainnya. Biasanya praktik semacam ini digunakan untuk meningkatkan awareness akun lain terhadap isu yang digunakan dalam mention atau hashtag yang dimaksud. Tabel 4 di atas adalah sedikit ilustrasi dari sejumlah akun yang paling banyak merujuk (out-degree) dalam hashtag \#PrabowoMenangDebat.

Di sini, peneliti akan melihat lebih detail dari dua akun yang memiliki tingkat out-degree paling tinggi, yaitu@siti_amahh dan @melliselviandin.

Tabel 5. Deskripsi Akun @siti_amahh

\begin{tabular}{|c|c|}
\hline Name & Siti Rahmah \\
\hline Joined Twitter on & Tue Dec 19 13:11:16 +0000 2017 \\
\hline Location & Kalimantan Selatan, Indonesia \\
\hline Popular topics & 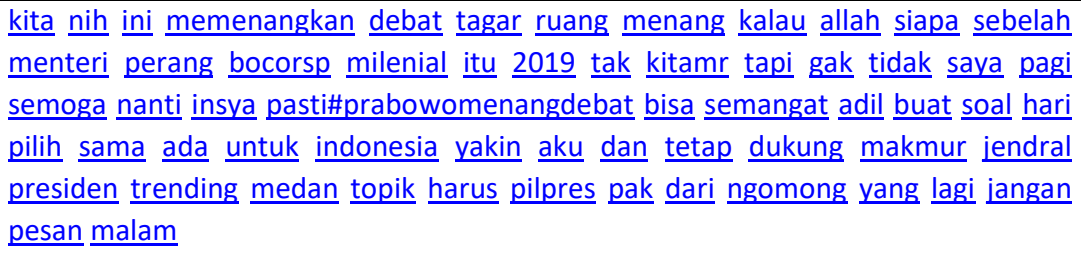 \\
\hline Popular hashtag & 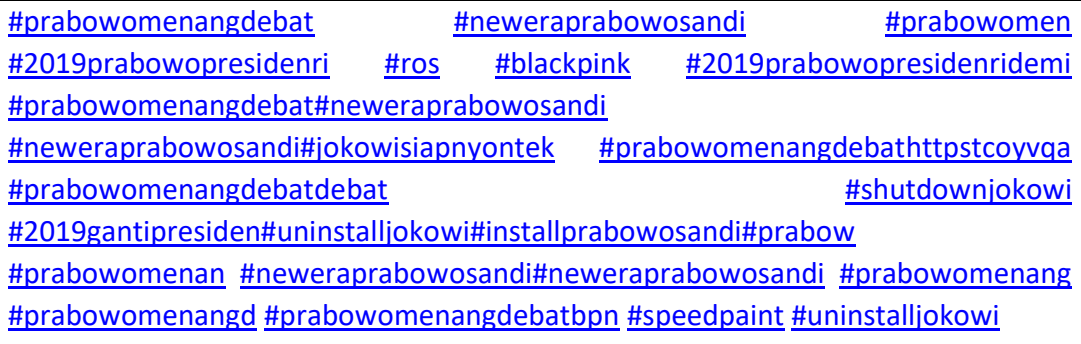 \\
\hline $\begin{array}{l}\text { Tweeted most at this } \\
\text { time }\end{array}$ & C (11PM Jakarta-time zone) 84 tweets on average at this particular time \\
\hline
\end{tabular}


Tabel 6. Deskripsi Akun @melliselviandin

\begin{tabular}{|c|c|}
\hline Name & Melli_Selviandini \\
\hline Joined Twitter on & Sun Aug 08 05:41:19+0000 2010 \\
\hline Location & Taichung city Taiwan \\
\hline Popular topics & 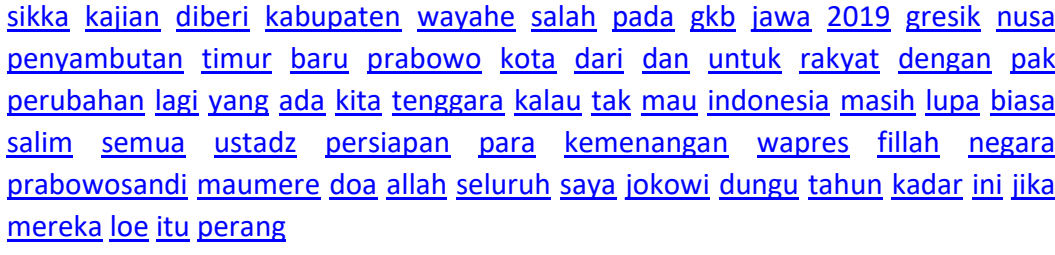 \\
\hline Popular hashtag & 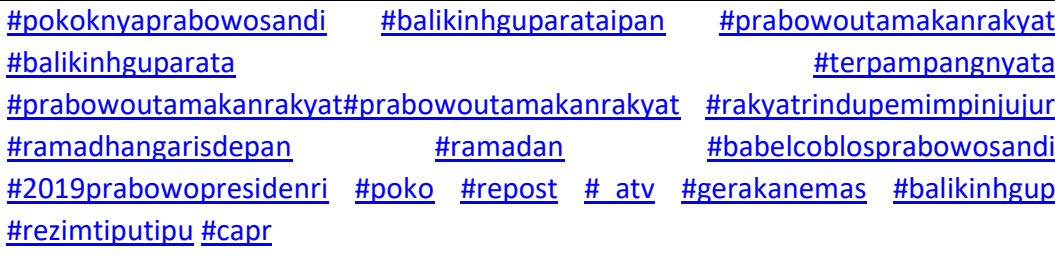 \\
\hline Most linked domains & $\begin{array}{l}\text { twitter.com, www.pscp.tv, youtu.be, hilalmerahindonesia.org, kominfo.go.id, } \\
\text { www.portal-islam.id, www.youtube.com, www.cendananews.com }\end{array}$ \\
\hline
\end{tabular}

Dari kedua sampel yang digunakan untuk menjelaskan komunikator yang paling aktif dalam merujuk (mention) dalam hashtag \#PrabowoMenangDebat dapat diketahui bahwa tidak selamanya kampanye dan komunikasi politik di media sosial dilakukan oleh bot politik. Dari contoh di atas, dapat diketahui bahwa kedua akun merupakan akun personal yang memang memiliki dedikasi yang cukup tinggi dalam mendukung calon presiden Prabowo Subianto. Kemudian, jika dilihat dari pola hashtag yang digunakan oleh kedua akun tadi, juga terlihat konsistensi dalam mempromosikan pesan-pesan politik yang sejalan dengan pesan kampanye dari pasangan Prabowo-Sandiaga. Artinya, komunikasi politik di media sosial yang dilakukan oleh pendukung Prabowo-Sandiaga lebih banyak berasal dari gerakan yang bersifat 'organik.' Akan tetapi, peneliti belum menemukan alat bukti yang lebih ilmiah untuk melihat sejauh mana akun yang dimaksud tadi bersifat authentic dan apakah memang pemilik akun beralamat sesuai dengan keterangan yang dipasang di profile akun Twitter mereka.

\section{Kasus Ketiga: \#DebatPintarJokowi}

Sementara itu, dari komunikasi politik oleh pendukung pasangan calon presiden dan wakil presiden Jokowi-Ma'ruf Amin, peneliti juga mendapatkan temuan yang menarik. Sebagai catatan, hashtag ini juga besar kemungkinan dibentuk oleh para pendukung pasangan Jokowi-Ma'ruf Amin. Adapun jaringan yang terbentuk dari unggahan terkait dengan hashtag \#DebatPintarJokowi dapat dilihat melalui Gambar 3 di bawah ini. 


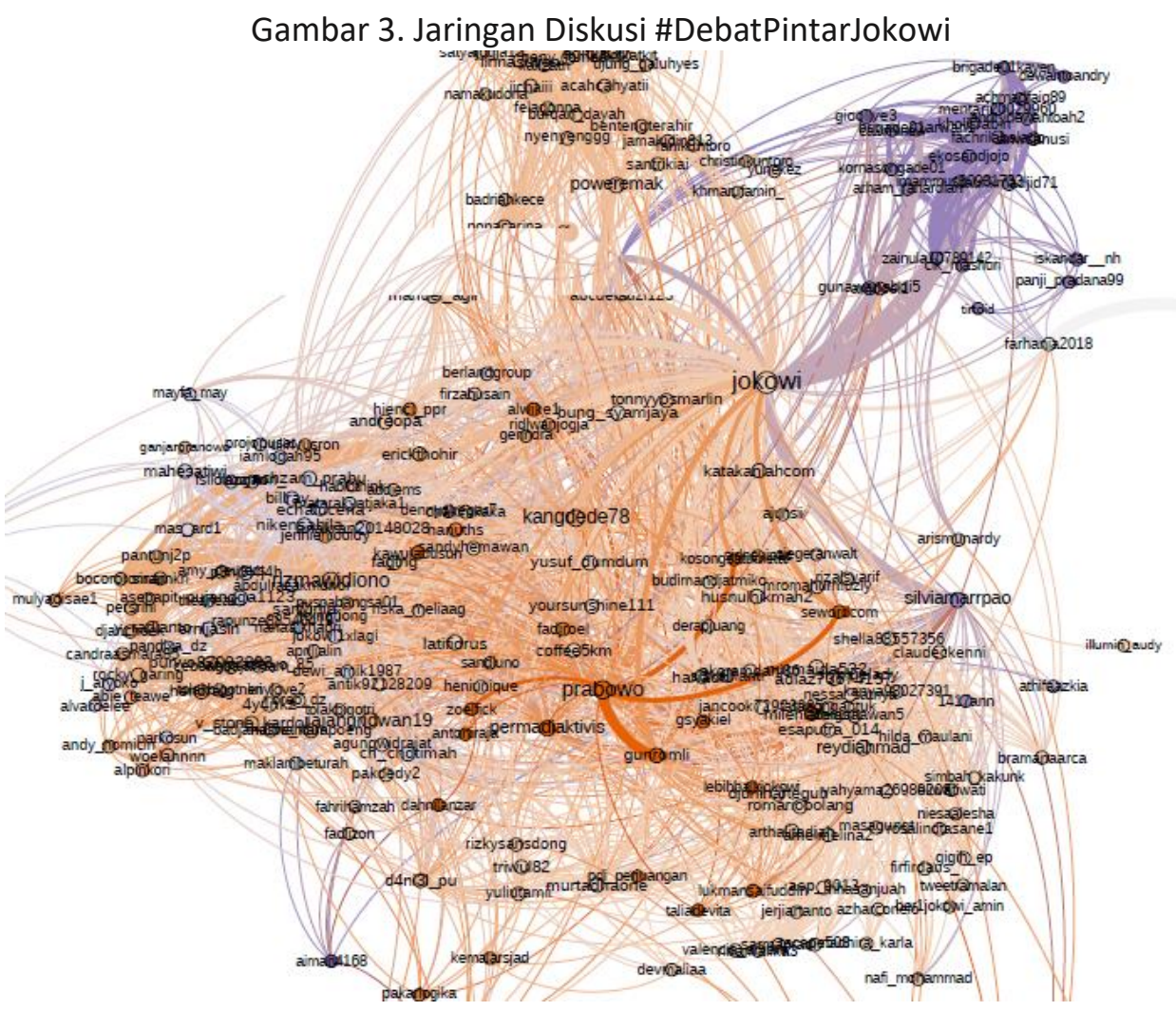

Berdasarkan analisis data tentang penggunaan hashtag \#DebatPintarJokowi didapatkan data random sebanyak 7.635 nodes dan 22.812 edges. Selain itu, dari modularity analysis, diketahui pula setidaknya ada 1.267 komunitas yang terbentuk terkait perbincangan menggunakan hashtag tersebut. Melalui hashtag \#DebatPintarJokowi dapat dilihat bahwa modularity yang terbentuk lebih melebar sehingga memungkinkan adanya banyak klaster atau kelompok diskusi yang lebih beragam. Secara visual dapat dilihat bahwa masing-masing warna mencerminkan kelompok diskusi yang berbeda-beda. Posisi akun @jokowi sendiri tidak terlalu dominan meskipun berada di antara sejumlah klaster yang berbeda. Menariknya, node size yang dimiliki akun @jokowi juga tidak terlalu dominan dan tidak terlalu kontras jika dibandingkan dengan akun penting lainnya di dalam jaringan hashtag \#DebatPintarJokowi di atas.

Akun lain yang juga memiliki posisi sentral dalam jaringan yang sama adalah akun @ prabowo. Posisi akun tersebut ada di tengah bagian bahwa layout jaringan dan juga berhubungan dengan sejumlah klaster yang berbeda warna dengan mereka yang merujuk akun @jokowi secara langsung (direct connection). Temuan ini dapat diartikan dengan dua cara. Pertama, akun @prabowo dibahas bersamaan dengan penyebutan @jokowi dalam konteks memuji performa debat yang ditampilkan oleh Jokowi dan membandingkannya dengan performa Prabowo. Kedua, akun @prabowo disebut sebagai sanggahan bahwa performa yang ditampilkan oleh Prabowo Subianto tidak kalah jika dibandingkan dengan \#DebatPintarJokowi, terutama mengingat bahwa perdebatan atau 'perang hashtag' juga dapat menggunakan strategi hashtag milik kubu lawan politik. 
Dalam hal penggunaan bahasa, seringkali pesan yang diunggah lebih condong kepada memuji kandidat presiden yang didukung dan menjatuhkan kandidat lainnya. Misalkan saja pesan berisikan sindiran bahwa @jokowi lebih menguasai materi debat (tentang energi, lingkungan, dan juga infrastruktur) sedangkan @prabowo disebut lebih 'menguasai lahan.' Sindiran ini didasari oleh pengakuan Prabowo Subianto dalam acara debat bahwa dia memiliki lahan seluas 220.000 hektar di Kalimantan Timur dan 120.000 hektar di wilayah Aceh Tengah. Di sisi lain, pendukung Prabowo Subianto juga menyindir pendukung Jokowi bahwa jika memang calon presiden tersebut memiliki niat baik untuk mengembangkan industri startup (atau disebut sebagai unicorn dalam konteks debat tersebut) di Indonesia, maka tidak seharusnya mereka melakukan kampanye \#UninstallBukalapak di media sosial.

Tabel 7. Contoh Isi Pesan dalam \#DebatPintarJokowi

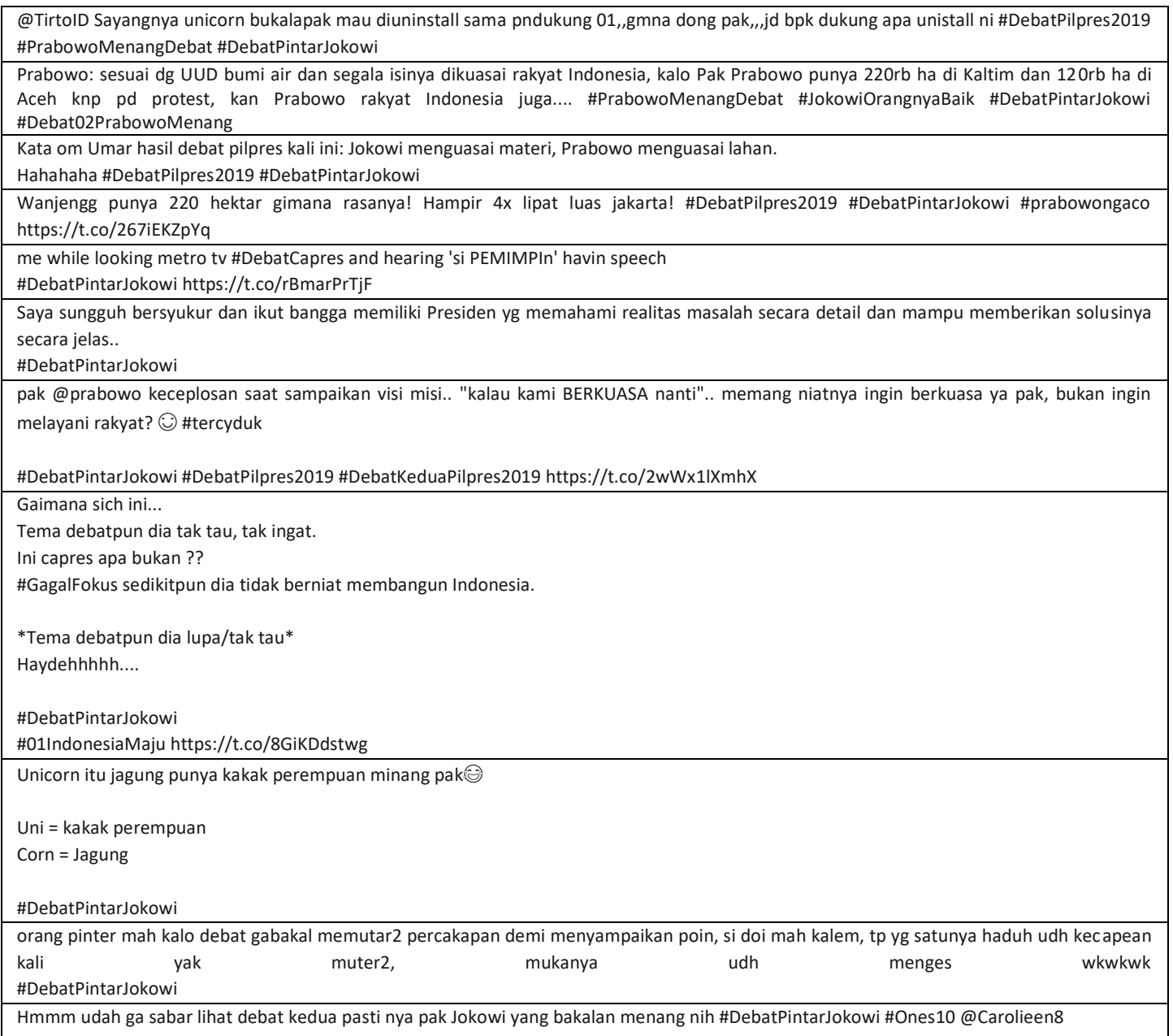




\section{PEMBAHASAN DAN SIMPULAN}

Menurut data dari Statista (2019), setidaknya ada 6,43 juta pengguna media sosial Twitter di Indonesia. Jumlah ini memang tergolong kecil jika dibandingkan dengan pengguna Facebook atau bahkan jumlah total penduduk di Indonesia. Dalam konteks jumlah pemilih atau mereka yang berhak mengikuti pemilihan umum di Indonesia pada April 2019, tentunya angka 6,43 juta pengguna Twitter bukanlah jumlah yang besar. Akan tetapi, bukan berarti opini pengguna di platform media sosial ini tidak dilihat penting oleh masyarakat luas, media massa, maupun oleh para aktor politik yang memiliki kepentingan.

Jika melihat dari data yang telah dipaparkan sebelumnya, secara umum dapat dikatakan bahwa banyak dari pengguna media sosial di Indonesia yang secara aktif ikut serta berbicara tentang politik akan tetapi hanya berkomunikasi dengan mereka yang memiliki pemahaman yang sama terkait dengan kelompok politik yang didukungnya -- atau secara ilmiah lebih umum disebut sebagai homophily. Kecenderungan ini juga ditemukan dalam riset Halberstam dan Knight (2016) tentang bagaimana publik di Amerika Serikat mendiskusikan politik di Twitter selama Pemilihan Umum 2012 di negara tersebut, di mana kelompok konservatif cenderung terhubung dengan sesama kelompok konservatif dan pendukung kelompok liberal juga lebih dekat dengan sesama mereka. Praktik homophily semacam ini adalah temuan yang lumrah dalam dua kasus penggunaan hashtag dalam unggahan pesan politik terkait dengan debat calon presiden Indonesia pada awal Februari 2019, terutama pada hashtags \#PrabowoMenangDebat dan \#DebatPintarJokowi di mana masing-masing hashtag digagas oleh pendukung dari salah satu kubu politik.

Dalam kasus yang lebih bersifat netral, yaitu dalam penggunaan hashtag \#DebatPilpres2019, para pendukung masing-masing kandidat dapat menyuarakan opini atau pandangan politik mereka dengan berbagai macam cara. Setidaknya peneliti menemukan tiga tipe penyebaran pesan dalam jaringan yang dianalisis. Pertama, ada sejumlah akun Twitter yang menggunakan hashtag ini dengan nada yang netral seperti membahas kelebihan dan kelemahan dari kedua kandidat atau sekedar menunggu gagasan yang akan ditawarkan oleh keduanya. Di sini, jaringan komunikasi yang bersifat dua arah atau lebih (seperti pesan yang menyebar kepada kubu politik yang lain) lebih mungkin terjadi. Kedua, ada banyak akun yang mengeksploitasi pesan yang mendukung kandidat pilihannya. Tidak sedikit dari pesan yang disampaikan oleh mereka lebih bersifat hiperbolik serta emosional daripada rasional. Pesan dalam strategi komunikasi politik semacam ini cenderung hanya satu arah. Ketiga, ada juga sejumlah akun Twitter yang tidak tertarik untuk mendukung kandidat pilihannya tapi justru lebih berupaya untuk menyindir atau bahkan menyerang kandidat lain. Pesan yang digunakan dapat bersifat halus (seperti penggunaan satir atau humor) tapi ada pula yang menggunakan kata-kata yang kasar. Pesan yang disampaikan dengan gaya komunikasi seperti ini juga lebih sedikit menghasilkan dialog yang konstruktif dari kedua kubu politik yang berkompetisi di Pemilihan Presiden 2019 tersebut. 
Jika dilihat dari aspek density, maka dapat dikatakan bahwa keterhubungan antar nodes dari ketiga hashtag tersebut cukup dekat, terutama pada hashtags \#PrabowoMenangDebat dan \#DebatPintarJokowi. Mengingat kedua hashtags ini berasal dari pendukung mereka masing-masing, hal ini masih sejalan dengan prinsip homophily yang telah dibahas sebelumnya. Pada hashtag \#DebatPilpres2019, density sedikit lebih longgar sehingga keterhubungan antar individu di dalamnya tidak sedekat kedua hashtag tadi. Padahal, tingginya tingkat density ini dapat memengaruhi tingkat pertukaran informasi antar anggota di dalam suatu jaringan (Himelboim, Smith, Rainie, Shneiderman \& Espina, 2017).

Temuan lain yang menarik adalah tentang tingginya modularity dari ketiga hashtags yang dibahas. Artinya, modularity yang tinggi mencerminkan banyaknya komunitas kecil yang tercipta dalam suatu jaringan. Jadi, meskipun secara density para individu tadi banyak yang saling terhubung akan tetapi hubungan antar mereka banyak terbentuk dalam kelompok-kelompok kecil. Sehingga, mereka yang mengunggah pesan politik tertentu belum tentu berhubungan secara langsung (semisal melalui praktik memberi like, comment, atau retweet) dengan individu lainnya meskipun sama-sama menggunakan hashtag yang serupa. Dapat disimpulkan bahwa ketiga jaringan perbincangan terkait Pilpres 2019 di Twitter ini lebih berbentuk divided network (Himelboim et al., 2017).

Hal lain yang perlu diingat adalah perbincangan soal pemilihan presiden dan beragam debat melalui hashtag yang digunakan tadi merupakan bagian dari proses panjang komunikasi politik yang dilakukan oleh tim dari kedua kubu politik, baik Jokowi-Ma'ruf Amin ataupun Prabowo-Sandiaga. Untuk itu, diskusi online tentang politik semacam ini seringkali dilihat sebagai bentuk ad hoc public dan cenderung bersifat sementara (Bruns \& Burgess, 2012). Konsekuensinya, hashtag tertentu dapat dengan cepat naik ke permukaan dan menjadi trending topic, atau diunggah oleh ratusan ribu pengguna (atau dapat juga diunggah oleh bot ataupun 'buzzer' politik), akan tetapi cenderung tidak berumur panjang. Misalkan saja, hashtag \#DebatPilpres2019 di awal Februari 2019 ini tidak bertahan lebih dari tiga hari dan selanjutnya hilang atau berganti dengan hashtag lain yang juga masih ada kaitannya dengan komunikasi politik kubu Jokowi maupun Prabowo.

Jaringan diskusi politik di media sosial semacam Twitter juga dapat menjadi ramai serta menghasilkan jaringan yang rumit dan padat jika isu yang diangkat oleh hashtag tersebut pada saat yang sama terhubung dengan peristiwa lainnya yang ramai dibicarakan oleh masyarakat ataupun muncul di halaman media massa. Sejumlah peneliti Swedia dan Australia misalkan menemukan bahwa unggahan di Twitter tentang pesan yang berhubungan dengan pemilihan umum biasanya akan sangat bergantung kepada isu yang muncul di pemberitaan media (Bruns \& Burgess, 2011; Larsson \& Moe, 2012). Oleh karenanya, tidak mengherankan suatu hashtag dapat dengan cepat meningkat volume pesannya jika pada saat yang bersamaan hadir peristiwa besar yang diliput secara intens oleh media massa tradisional. Hal ini terbukti dalam ketiga kasus hashtag \#DebatPilpres2019 yang muncul bersamaan dengan siaran langsung acara debat antara 
Jokowi dan Prabowo di televisi maupun streaming di internet. Sebelumnya, muncul perang hashtag antara kubu pendukung Jokowi dalam kampanye \#UninstallBukalapak (yang merupakan suatu sindiran terhadap CEO e-commerce Bukalapak yang dianggap sebagai pendukung Prabowo) yang kemudian dibalas dengan hashtag lain setelahnya seperti kampanye \#DukungBukalapak, \#UninstallJokowi dan \#ShutDownJokowi yang dilakukan oleh para pendukung Prabowo.

Pada akhirnya, menjadi penting bagi penelitian selanjutnya untuk tidak hanya mengambil satu atau dua kasus hashtag terkait isu politik dengan pendekatan cross-sectional. Akan lebih baik jika ada kajian yang membahas tentang hashtag atau kata kunci tertentu yang dapat diamati dalam kurun waktu yang lebih lama dengan pendekatan longitudinal study, misalkan dalam jangka waktu satu atau dua semester atau bahkan lebih. Hal ini menjadi penting karena proses komunikasi politik seringkali adalah proses jangka panjang dan juga tidak selamanya diskusi politik di media sosial bersifat sementara.

Selain itu, karena pesan-pesan politik yang diunggah di media sosial seperti Twitter acapkali lebih bernuansa emosional dibandingkan rasional, maka penggunaan analisis sentimen untuk memahami pesan politik juga diharapkan dapat menangkap apa yang tidak dapat dilihat hanya melalui analisis jaringan (social network analysis). Untuk itu, riset selanjutnya juga sebaiknya menggunakan pendekatan yang lebih mengakomodir kemampuan menganalisis aspek emosi, termasuk juga dalam penggunaan pesan berbasis non-text seperti penggunaan foto, memes, gif, atau video pendek dan bentuk pesan audio-visual lainnya. Lebih dari itu, juga penting bagi riset selanjutnya untuk melakukan kajian yang lebih mendalam sejauh mana praktik komunikasi politik di media sosial didominasi oleh cyber troops ataupun bot politik.

\section{REFERENSI}

Amirullah, F., Komp, S., \& Nurhadryani, Y. (2013). Campaign 2.0: An analysis of the utilization social network sites of political parties in Indonesia. In ICACSIS 2013: International Conference on Advanced Computer Science and Information Systems (pp. 243-248). Washington, DC: IEEE Computer Society. DOI:10.1109/ICACSIS.2013.6761583

Bimber, B. (2014). Digital media in the Obama Campaigns of 2008 and 2012: Adaptation to the personalized political communication environment. Journal of Information Technology \& Politics, 11(2), 130-150.

Bruns, A. \& Burgess, J. (2011). \#ausvotes: How Twitter covered the 2010 Australian federal election. Communication, Politics \& Culture, 44(2), 37-56.

Bruns, A. \& Burgess, J. (2012). Notes toward the scientific study of public communication on Twitter. Keynote presented at the Conference on Science and the Internet. Dusseldorf, Augus 4, 2012.

Bruns, A., Enli, G., Skogerbø, E., Larsson, A. L., \& Christensen, C. (Eds.)(2016). The routledge companion to social media and politics. New York: Routledge.

Enli, G., \& Simonsen, C-A. (2018) 'Social media logic' meets professional norms: Twitter hashtags usage by journalists and politicians. Information, Communication \& Society, 21(8), 1081-1096. DOI: 10.1080/1369118X.2017.1301515 
Gainous, J., \& Wagner, K. W. (2014). Tweeting to power: The social media revolution in American politics. Oxford: Oxford University Press.

Gerodimos, R. \& Justinussen, J. (2014). Obama's 2012 Facebook campaign: Political communication in the age of the like button. Journal of Information Technology \& Politics, 00, 1-20.

Halberstam, Y., \& Knight, B. (2016). Homophily, group size, and the diffusion of political information in social networks: Evidence from Twitter. Journal of Public Economics, 143, 73-88. https://doi.org/10.1016/j.jpubeco.2016.08.011.

Hill, D. T. \& Sen, K. (2005). The internet in Indonesia's new democracy. London; New York: Routledge.

Himelboim, I., Smith, M. A., Rainie, L., Shneiderman, B., \& Espina, C. (2017). Classifying Twitter Topic-Networks Using Social Network Analysis. Social Media + Society, 3(1). https://doi.org/10.1177/2056305117691545

Jungherr, A. (2016) Twitter use in election campaigns: A systematic literature review. Journal of Information Technology \& Politics, 13(1), 72-91. DOI: 10.1080/19331681.2015.1132401

Jürgens, P., \& Jungherr. A. (2014). The use of Twitter during the 2009 German national election. German Politics, 24(4), 469-490. DOI: 10.1080/09644008.2015.1116522

Klinger, U. (2013). Mastering the art of social media: Swiss parties, the 2011 national election and digital challenges. Information, Communication \& Society, 16(5), 717-736. DOI: $10.1080 / 1369118 X .2013 .782329$

Larsson, A. O., \& Moe, H. (2012). Studying political microblogging: Twitter users in the 2010 Swedish election campaign. New Media \& Society, 14(5), 729-747. https://doi.org/10.1177/1461444811422894

Lim, M. (2012). Clicks, cabs, and coffee houses: Social media and oppositional movements in Egypt, 2004-2011. Journal of Communication, 62(2), 231-248. https://doi.org/10.1111/j.1460-2466.2012.01628.x

Lim, M. (2013). Many clicks but little sticks: Social media activism in Indonesia. Jurnal of Contemporary Asia, 43(4), 636-657.

McDaniel, D. O. (2002). Electronic tigers of Southeast Asia: The politics of media, technology and national development. Ames, IA: Iowa State University Press.

Rambukkana, N. (2015). \#Introduction: Hashtags as technosocial events. In N. Rambukkana, (Ed.), Hashtag publics: The power and politics of discursive networks, edited by Nathan Rabukkana (pp. 1-12). New York: Peter Lang Publishing

Setianto, Y. P. (2015). Media policy in the context of global media flows, the internet, and piracy: A historical analysis of media regulation in Indonesia. Jurnal Komunikasi: Malaysian Journal of Communication, 31(2), 371-388.

Statista. (2019). Number of active Twitter users in selected countries. Retrieved from https://www.statista.com/statistics/242606/number-of-active-twitter-users-inselected-countries/

Takaragawa, S., \& Carty, V. (2012). The 2008 US Presidential Election and new digital technologies: Political campaigns as social movements and the significance of collective identity. Tamara Journal of Critical Organization Inquiry, 10(4), 73-89.

Tufekci, Z. (2017). Twitter and tear gas: The power and fragility of networked protest. New Haven: Yale University Press. 
Vromen, A. (2017). Digital citizenship and political engagement: The challenge from online political campaigning and advocacy organizations. London: Palgrave Macmillan.

Wojcieszak, M. E., \& Mutz, D. C. (2009). Online groups and political discourse: Do online discussion spaces facilitate exposure to political disagreement? Journal of Communication, 59(1), 40-56. https://doi.org/10.1111/j.1460-2466.2008.01403.x 